\title{
Metabolism, personality and pace of life in the Trinidadian guppy, Poecilia reticulata
}

\author{
S.J. White *, T.J. Kells and A.J. Wilson \\ Centre for Ecology and Conservation, University of Exeter (Penryn Campus), \\ Treliever Road, Penryn, Cornwall TR10 9FE, UK \\ *Corresponding author's e-mail address: s.j.white@exeter.ac.uk
}

Accepted 24 May 2016; published online 9 June 2016

\begin{abstract}
While among-individual variation in behaviour, or personality, is common across taxa, its mechanistic underpinnings are poorly understood. The Pace of Life syndrome (POLS) provides one possible explanation for maintenance of personality differences. POLS predicts that metabolic differences will covary with behavioural variation, with high metabolism associated with risk prone behaviour and 'faster' life histories (e.g., high growth, early maturation). We used a repeated measures approach, assaying metabolic traits (rate and scope), behaviour and growth to test these predictions in the Trinidadian guppy, Poecilia reticulata. We found that while individuals varied significantly in their behaviour and growth rate, more risk prone individuals did not grow significantly faster. Furthermore, after accounting for body size there was no support for amongindividual variation in metabolic traits. Thus, while personality differences are clearly present in this population, they do not covary with metabolism and the POLS framework is not supported.
\end{abstract}

\section{Keywords}

animal personality, risk taking behaviour, Pace of Life Syndrome, metabolism.

\section{Introduction}

Among individual variation in behaviour, or personality, is widespread across taxa, yet our knowledge of the mechanisms driving and maintaining this variation is limited. The Pace of Life Syndrome (POLS) predicts that behaviour and life history covary with physiology along a slow-fast axis (Ricklefs \& Wikelski, 2002; Réale et al., 2010). Individuals with higher metabolic rates are predicted to grow more quickly on average, mature earlier, invest in less responsive immune machinery, have more offspring per 
reproductive bout, and have a reduced longevity. POLS also predicts that a fast pace-of life will be associated with more 'risk prone' behavioural types (Briffa et al., 2015) typically defined by greater boldness, exploratory tendency, and/or aggressiveness (Réale et al., 2010).

These patterns are relatively well supported by studies comparing suites of traits at among-species and among-population levels. For instance, tropical bird species that live longer have, on average, lower metabolic rates than temperate species (Wiersma et al., 2007; Williams et al., 2010). In addition, species of wild rodent with a faster pace of life rely more on innate immune responses than more expensive adaptive machinery (Previtali et al., 2012), a pattern also seen among populations of house sparrows (Passer domesticus) (Martin et al., 2006). Empirical studies of behavioural traits have also found correlations as predicted by POLS. For instance Careau et al. (2010) found that domesticated dog breeds that were more trainable and obedient lived longer than more aggressive breeds that had higher metabolisable energy intakes. Bird species exhibiting riskier flight behaviour have higher metabolic rates (Møller, 2009). Populations of Trinidadian guppies, Poecilia reticulata, exposed to higher levels of predation tend to exhibit fast growth, early maturation and more risk-prone behaviours (e.g., emerging more rapidly from shelter in personality trials) (Reznick et al., 1996; Bronikowski et al., 2002; Harris et al., 2010).

With behaviour, life history and physiology seemingly well integrated at the among species/population level, it is intuitive to ask whether the POLS framework might also explain among-individual variation within populations, including the widespread presence of animal personality (Careau et al., 2008; Réale et al., 2010). If different combinations of metabolic rate, growth and behaviour confer similar lifetime fitness, among-individual variation in these traits may be maintained and significant correlations between traits should persist (Biro \& Stamps, 2010; Réale et al., 2010). Individuals exhibiting more risk-prone tendencies (e.g., being bolder, more exploratory or more aggressive) are likely to encounter or acquire more resources at the expense of increased mortality risk from predation, whereas risk-averse individuals may acquire fewer resources but experience less mortality risk. Thus, if optimal growth rate varies among-individuals, perhaps because of underlying metabolic variation, risky behaviours should correlate positively with growth (Ward et al., 2004; Stamps, 2007; Mas-Muñoz et al., 2011). This can be expanded further by considering trade-offs between current and future 
reproductive success: if future reproduction is unlikely, then it pays to employ risky behaviours to gain the resources to fuel a high growth rate. All else being equal, in juveniles, rapid growth facilitates earlier reproduction, while in organisms with indeterminate growth, fast adult growth typically delivers increased fecundity. Conversely, future reproductive prospects may be enhanced by being risk-averse, thus decreasing mortality risk (e.g., from predation), but also resulting in delayed maturation and slower growth (Wolf et al., 2007; Biro \& Stamps, 2008).

Applied within populations, the POLS framework predicts a positive relationship between metabolic rate and risky personalities, although causality is potentially bidirectional. For instance, if risk-prone individuals have higher food intake they may develop larger food processing organs (liver, intestines etc) that have high mass specific metabolic rate (Biro \& Stamps, 2010; Careau \& Garland, 2012; Wiersma et al., 2012) (but see Russell \& Chappell, 2007, who found no relationship between organ mass and basal metabolic rate). Alternatively, individuals with high metabolism and therefore high base energetic requirements may be compelled to take risks (e.g., by needing to feed sooner after a disturbance than those with lower metabolic costs), resulting in a risk-prone behavioural phenotype (Finstad et al., 2007; Careau et al., 2008). Despite this uncertainty over causation, positive relationships between behaviour and metabolic rate consistent with the POLS framework have been found among-individuals in a range of species, including several fishes (McCarthy, 2001; Cutts et al., 2002; Huntingford et al., 2010; Robertsen et al., 2013). The evidence, however, is far from conclusive since Bouwhuis et al. (2014) actually found a weak negative correlation between exploratory behaviour and basal metabolic rate in female (but not male) great tits (Parus major). In the same species, Mathot et al. (2014) found that the sign of the correlation between basal metabolic rate and postdisturbance time to resume feeding depended on the type of disturbance. Context dependent correlations between metabolic traits and risk related behaviours have been reported in juvenile sea bass (Dicentrarchus labrax) (Killen et al., 2011, 2012), while several have reported no relationship at all in salamanders (Desmognathus brimleyorum), root voles (Microtus oeconomus) and common lizards (Zootocai vipara) (Lantová et al., 2011; Le Galliard et al., 2013; Gifford et al., 2014).

A possible reason for the mixed support for the predictions of POLS is that, while most studies to date have focused on basal, resting or standard 
metabolic rate, metabolic scope may be a more important determinant of the link between individual physiology and behaviour (Careau \& Garland, 2012; Mathot \& Dingemanse, 2015; Metcalfe et al., 2015). Metabolic scope (MS) can be viewed as the energetic capacity, after base metabolic demands are met, available for processes such as exhibiting behaviours. If individuals vary in MS this could potentially drive and maintain among-individual variation in behaviour. Importantly, relationships between resting metabolic rate and MS vary across species (Cutts et al., 2002; Speakman et al., 2003; Hansen \& Hunt Von Herbing, 2009; Careau et al., 2013, 2015), potentially limiting the generality of resting metabolic rate-based investigations of POLS (Mathot \& Dingemanse, 2015). In addition, assessing among-individual (co)variation requires repeated measures of all traits concerned (Nakagawa \& Schielzeth, 2010). While recent years have seen an increase in the use of repeated measures approaches to the study of behaviour and physiology, more studies taking an integrated approach with multiple measures of each individual are required to fully understand POLS within populations.

The aim of this study is to evaluate the POLS framework in Trinidadian guppies (henceforth guppies). We use a captive population of guppies and a multivariate repeated measures approach to assess the (co)variance structure between metabolic rate and scope, risk related personality traits and growth rate. If POLS is present in this population we predict that (i) individuals will differ consistently in metabolic traits (metabolic rate and scope), (ii) individuals will show personality differences consistent with risk prone-risk averse continuum of behavioural variation and (iii) metabolic and behavioural traits will be correlated at the individual level, with fast paced individuals (high metabolic rate, risk-prone) also showing faster growth rates than slower paced conspecifics.

\section{Materials and methods}

\subsection{Study species}

Guppies used in this experiment were from a captive population housed at the University of Exeter's Penryn campus fish facility. The population is descended from wild individuals caught in 2008 from a high predation site in the lower Aripo River, Trinidad (ca. 18-20 generations ago) and has been maintained at an effective population size of several thousand (with no deliberate selection or inbreeding). 
Thirty-two adult females were sampled from the stock population and tagged using visible implant elastomer tags (VIE). Sampling was haphazard but we tried to limit size variation by selecting fish of similar size. The tagging process consisted of submersion in an $80 \mathrm{mg} / \mathrm{l} \mathrm{MS} 222$ solution buffered with sodium bicarbonate for several minutes, until fish stopped swimming and rested on the tank floor. Sedated fish were then tagged and placed immediately into a large, well-aerated tank and monitored for $5 \mathrm{~min}$, during which all fish recovered from anaesthesia. VIE tags have been shown to have no significant effect on growth or behaviour in zebrafish (Danio rario) and guppies (Croft et al., 2004; Hohn \& Petrie-Hanson, 2013) and there was no tagging related mortality in this experiment.

As isolation can cause unnecessary stress, each fish was randomly allocated to one of 4 groups ( 8 individuals per group). Groups were housed in separate home tanks $(151,18.5 \times 37 \times 22 \mathrm{~cm})$ but shared a common recirculating sump water supply, maintained at $23-24^{\circ} \mathrm{C}$ and on a $12: 12$ light/dark cycle. The tank stack used was a well aerated closed system subject to a $25 \%$ water change once per week with weekly tests for ammonia, nitrite and nitrate levels. All fish were fed to satiation twice daily on commercial flake food and live brine shrimp (Artemia salina) nauplii. Female guppies are indeterminate growers, continuing to exhibit significant growth well after maturity, making them ideal to test the predictions of POLS. Males were excluded from this study as growth rate is much lower post maturity.

The experiment was conducted under the auspices of the Animals (Scientific Procedures Act) under licence from the Home Office (UK) and with local ethical approval from the University of Exeter. All periods of handling and emersion were kept as short as possible. At the end of the experiment, fish were moved to a 'retirement' stock tank (containing males and other females) and allowed to reproduce to contribute to the stock population. These fish were not subject to any further licensed procedures.

\subsection{Experimental design}

We used a repeated measures approach to test for among-individual (co)variation in metabolic rate, personality and growth. Metabolic rate was assessed from intermittent flow respirometry while personality was assessed using two behavioural testing paradigms (open field trials, OFT and emergence trials, ET). Individuals from all groups experienced a sequence of phenotypic assays comprising: day 1 , OFT; day 2 , routine metabolic rate 
(RMR); day 4, ET; and day 5, active metabolic rate (AMR). We repeated this week one sequence for a second week. Fish were then subject to two additional OFT and ET each. These were conducted in weeks 7 and 9 for groups 1 and 2 (with one trial per type per week per fish). However, due to space and equipment constraints, we conducted these additional trials in weeks 4 and 6 for groups 3 and 4 . This difference is controlled for statistically in the analysis. Standard length (measured from tip of snout to end of caudal peduncle, in $\mathrm{mm}$ ) and mass were measured at every behavioural and metabolic trial and 1 month after the final behavioural trial experienced by each fish to allow calculation of growth rate. Emersion time to conduct these measures (which were not conducted under anaesthetic) was typically less than $10 \mathrm{~s}$ and fish were fully recovered several minutes after being returned to the tank.

In total, each fish had 4 metabolic measures, 4 OFT, 4 ET and 13 size measures with total data collection spanning 13 (groups 1 and 2) or 10 (groups 3 and 4) weeks. At each sampling, the order (i.e., 1-8) in which each fish was haphazardly captured from its group tank was also recorded.

Our experimental design should have led to 128 metabolic trials (64 RMR, 64 AMR) and 256 behavioural trials (128 OFT, 128 ET). However, we experienced some mortality late in the data collection period and incomplete data were thus obtained for 9 individuals (with 120 metabolic and 215 behavioural trials completed). Based on the absence of adverse effects attributable to the protocols a general water quality problem in the facility was the suspected cause, although age may also be a factor (fish were sampled from a stock tank containing larger and, since female guppies exhibit indeterminate growth, putatively older than average fish). In the following analyses we used all available data, however, including individuals with incomplete data collection since the mixed model analyses used are robust to unbalanced data sets. We also account for cumulative trial number and group size in all statistical models (see statistical methods below) to avoid any potential for bias.

\subsection{Metabolic measures}

An automated intermittent flow respirometer from Qubit biological systems (http://qubitsystems.com) was used to measure metabolic rate. The respiration chamber $(1.6 \times 4.5 \mathrm{~cm}, 9 \mathrm{ml})$ was submerged in a $2.5-1$ water bath with water temperature maintained at $24^{\circ} \mathrm{C}\left(23.9-24.1^{\circ} \mathrm{C}\right)$ using a submersible 
heater (Visi-therm $25 \mathrm{~W}$, www.aquariumsolutions.eu) and a UV steriliser to minimise bacterial growth. $R M R$ is here defined as the metabolic rate of a post-absorptive non-reproductive fish at rest while including random movement required to maintain position in the water column (Killen et al., 2011). Guppies, even at rest, still exhibit some tail and fin movement to maintain position in the water; we were unable to account for this movement and therefore we define our measures as RMR rather than standard metabolic rate (SMR). One could argue that such random movements are a necessary part of the metabolic expenditure when an aquatic organism is at rest and should not be removed at all.

To measure RMR, the focal fish was placed in the respiration chamber following $24 \mathrm{~h}$ of fasting. Oxygen consumption was then measured over four 10-min 'closed' periods (i.e., chamber and pump closed off from the water bath) separated by 4-min 'flush' periods. Standard length and mass were measured immediately after every metabolic trial to be used to calculate mass-specific metabolic traits (see below). RMR was estimated as the average of the last three oxygen consumption rates (each determined as the slope over the most stable part of the corresponding 10-min period in $\mathrm{mg}$ $\mathrm{O}_{2} / \mathrm{l}$ per s). The first metabolic rate measure of each trial was excluded as pilot trials suggested it was significantly higher, likely reflecting a response to the physical stressor of being moved into the respirometer. AMR was measured similarly, but immediately following 2 min of being chased by a hand net. The aim of the net chasing was to provoke a 'burst and glide' swimming technique that has been found to be aerobically demanding (Cutts et al., 2002; Norin \& Malte, 2011). Due to ethical considerations we did not measure true maximal metabolic rate (MMR) as this requires exercising the fish to complete exhaustion, which in guppies may have resulted in mortality. AMR was estimated as the rate of oxygen consumption from the first 2 min of being in the respiration following the chasing. See supplementary methods for further details on respirometer use and setup.

\subsection{Behavioural trials}

\subsubsection{Open field trial}

Our OFT followed a protocol very similar to that described by Boulton et al. (2014). The focal fish was placed into an empty tank $(30 \times 20 \times 20 \mathrm{~cm})$ with $5 \mathrm{~cm}$ water depth, and lit from below using a light box. A video camera fixed above the tank allowed the movement of the fish to be tracked using 
Viewer software (http://www.biobserve.com), removing observer bias and minimising measurement error. Placing a cardboard screen around the tank during the trials prevented disturbance by researcher activity. Following $30 \mathrm{~s}$ of acclimation, a 4 min $30 \mathrm{~s}$ tracking period was used to determine total tracklength swum $(\mathrm{cm})$, activity (percent time swimming above $4 \mathrm{~cm} / \mathrm{s}$ ) and percent of tank area covered. We also recorded the amount of time spent in an outer 'safe' zone near to the side of the tank and an inner 'risky' zone (Henceforth, Time in middle), the zones being defined as equal in size following Boulton et al. (2014). These behaviours have been shown to predict risky or 'bold' personality effectively in other poeciliid fishes (Burns, 2008; Boulton et al., 2014), with bolder individuals expected to have a longer track length, be more active, cover more tank area, and spend more time in the 'risky' middle tank zone. The water in the OFT tank was changed between each group of fish. We controlled for any effects of order of testing (within group) that might arise due to, for instance, release of hormones or other chemicals into the tank by including order caught as a fixed effect in models for all traits in our statistical analysis (see below).

\subsubsection{Emergence trial}

The focal fish was placed in a shelter area within a larger tank $(40 \times 20 \times$ $20 \mathrm{~cm}$ ) filled to $8 \mathrm{~cm}$ depth and screened as described above with a video camera placed overhead. It was allowed to acclimate for $30 \mathrm{~s}$ before a sliding door in the shelter wall was opened, allowing access to the rest of the tank. Time to emergence (henceforth emergence time) was then recorded and trials were ended at emergence or at $15 \mathrm{~min}$ if the fish had not emerged by this time (6 out of 106 trials).

\subsection{Statistical methods}

We used a series of univariate and multivariate linear mixed effect models to test among-individual (co)variation in metabolic traits, personality and growth as predicted by POLS. Random regression methods were used to characterise variation in $M S$ and growth as described fully below. We applied a $\log$ transformation to metabolic rate data to help control for size effects (since the relationship between metabolic rate and weight appeared linear on a log-log scale) and to emergence time to reduce slight positive skew. We also mean-centred all (transformed) traits and scaled them to standard deviation units. This was to facilitate multivariate model convergence and prevent different trait scales from driving conclusions. Linear mixed effects models 
were then fitted with restricted maximum likelihood (REML) using ASReml 4.0 (http://www.vsni.com). Conditional $F$ statistics were used to determine significance of all fixed effects while inference on random effects used likelihood ratio tests (LRT). Twice the difference in log-likelihood between full and reduced models was assumed to be distributed as $\chi^{2}$ with degrees of freedom (df) equal to the number of additional parameters in the full model. For testing a single variance component only, we assumed a 50:50 mix of $\chi_{0}^{2}$ and $\chi_{1}^{2}$ (subsequently denoted $\chi_{0,1}^{2}$ ), following the recommendations of Visscher (2006).

\subsubsection{Metabolic traits}

Univariate models containing individual as a random effect were fitted to the metabolic rate data. Repeatability (conditional on fixed effects) was then calculated as the intraclass correlation, $R=V_{\mathrm{I}} /\left(V_{\mathrm{I}}+V_{\mathrm{R}}\right)$, where $V_{\mathrm{I}}$ is the among-individual variance and $V_{\mathrm{R}}$ is the residual variance (Nakagawa \& Schielzeth, 2010). We included fixed effects of group, trial number (the cumulative number of trials of any type previously experienced), order caught (1-8 within each group) and measure type (RMR or AMR). The group effect controls for differences in physical and social environments among tanks. Order caught refers to the order in which each fish in a group was assayed on a trial day and is intended to account for any cumulative disturbance effect of removing fish sequentially from the home tank. The measure type fixed effect accounts for any differences between mean RMR and mean AMR measures, allowing all 4 measures per individual to be included in the calculation of repeatability.

This model tests for among-individual variance in metabolic rate (across routine and active contexts) as well as for the expected increase in average oxygen consumption with activity. We then characterised variation in MS by adding a random interaction of fish identity with measure type to the above model. Measure type was treated as a continuous variable indicative of activity level and arbitrarily scaled (such that at RMR activity $=-0.5$, and at AMR activity $=0.5$ ). Note that conventionally MS is measured as the difference between standard (SMR) and maximal metabolic rates (MMR), neither of which were formally assayed in our experiment. However, MS can equally be represented as the slope of an individual's reaction norm between two activity states on an arbitrarily scaled axis (i.e., 'standard' and 'maximal'; Figure 1). Since a slope is defined by any two points on the reaction norm, we are able to characterise rank order variation in MS using 


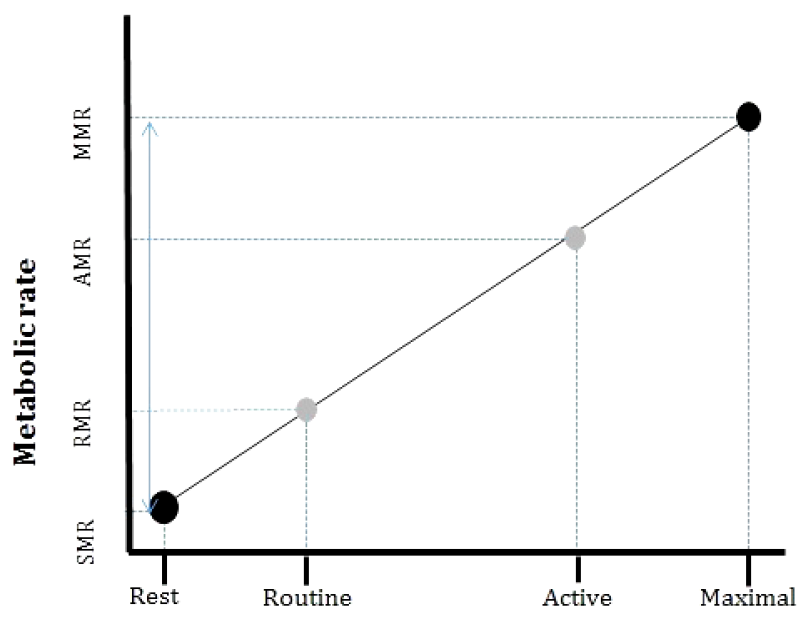

\section{Activity Level}

Figure 1. Metabolic scope (MS) is defined as the difference between standard metabolic rate (SMR) and maximal metabolic rate (MMR) (blue arrow) but can equally be determined as the slope of a reaction norm (black line) between resting and maximal activity states (black circles). Here we use observations of routine metabolic rate (RMR) and active metabolic rate (AMR) made at intermediate activity levels (grey circles) to infer the reaction norm slope. This figure is published in colour in the online edition of this journal, which can be accessed via http://booksandjournals.brillonline.com/content/journals/1568539x.

assays of metabolic rate at intermediate 'routine' and 'active' levels instead (Figure 1). Although complete correspondence is strictly contingent upon a linear reaction norm through all four activity states (Figure 1), in practice the RMR-AMR reaction norm slope will be strongly correlated to, and thus a suitable proxy for, MS as standardly defined over a much wider range of scenarios. The reaction norm framework, using random regression, allows the value of a random effect to vary with an additional covariate. This technique has been used extensively to model among-individual variation in morphological and life history traits as well as genotype-by-environment interactions (Nussey et al., 2007; Dingemanse et al., 2010; Roff \& Wilson, 2014). Both models were first fitted using log metabolic rate data uncorrected for mass. We then refitted with $\log$ body mass as an additional fixed covariate such that $V_{\mathrm{I}}$ is interpretable as variance in mass-specific metabolic rate while (in the reaction norm formulation) among-individual variance in slope $\left(V_{\mathrm{S}}\right)$ is interpretable as variance in mass-specific MS. 


\subsubsection{Behavioural traits}

Behavioural traits were similarly modelled with a random effect of individual and fixed effects of temperature, group, order caught, trial number and weight. Interestingly pilot analysis indicated that the order caught was itself repeatable, and so this was modelled as an additional behaviour potentially indicative of risk-taking (note order caught was necessarily not fitted as a fixed effect in this case). Following Boulton et al. (2014), we then fitted a multivariate mixed model with all 6 behavioural traits (i.e., tracklength, activity, area covered, time in middle from OFT; emergence time from ET; and, order caught from both OFT and ET). This allowed us to test the prediction that all OFT behaviours would be positively correlated with each other at the individual level and negatively correlated with emergence time and order caught, consistent with an underlying axis of shyness-boldness. The resulting variance/covariance matrix was subject to eigenvector decomposition, allowing us to identify the major axes of variation and see how the behavioural traits load on to these axes. Eigenvector decomposition is analogous to principle component analysis, but used here to describe only the among-individual component of phenotypic (co)variance, after partitioning the component (Wilson et al., 2011a; Boulton et al., 2014).

\subsubsection{Growth}

Among-individual variation in growth was also characterised using random regression mixed models of standard length that included random effects of fish identity and a fish by time since start of experiment interaction (zero centred from an actual mean across all size measurements of 25 days). Fixed effects included were group, last day seen (to account for mortality effects on average growth) and time since start of experiment (days) as a linear covariate to account for average growth. We chose a simple linear function because actual age of fish was unknown (though all females were mature) and growth was observed over a short period only. In this model $V_{\mathrm{I}}$ is interpretable as the among-fish variation in standard length at the intercept (i.e., 25 days from the start of the experiment) while the variance in individual regression slopes $\left(V_{\mathrm{S}}\right)$ is among-fish variance in growth rate. Finally, standard length was added to the above multivariate model to assess the among-individual (co)variance structure of size and growth with behaviour. 
Table 1.

Estimated repeatabilities of behavioural traits (conditional on fixed effects) assayed in open field and emergence trials.

\begin{tabular}{lccr}
\hline Trait & Repeatability & $\chi_{0,1}^{2}$ & \multicolumn{1}{c}{$p$} \\
\hline Emergence time & $0.33(0.12)$ & 9.37 & 0.001 \\
Track length & $0.31(0.12)$ & 6.84 & 0.005 \\
Activity & $0.37(0.12)$ & 9.32 & 0.001 \\
Order caught & $0.27(0.07)$ & 66.40 & $<0.001$ \\
Area covered & $0.46(0.11)$ & 21.80 & $<0.001$ \\
Time in middle & $0.42(0.12)$ & 14.40 & $<0.001$ \\
\hline
\end{tabular}

Estimates are from univariate models with standard errors in parentheses.

\subsection{Data used}

All data used are available as supplementary material in the online edition of this journal, which can be accessed via http://booksandjournals.brillonline. com/content/journals/1568539X.

\section{Results}

While whole animal metabolic rate shows significant among-individual variation $\left(R=0.27(0.11), \chi_{0,1}^{2}=8.031, p=0.002\right)$, inclusion of $\log$ (weight) as a fixed effect results in the estimate of $V_{\mathrm{I}}$ being bound to zero to stay in allowable parameter space. We thus estimate a repeatability of zero for mass-specific metabolic rate (across the two activity levels). Furthermore, comparison of the random regression model to this simple formulation provide no evidence that individuals vary significantly in either whole animal $\operatorname{MS}\left(\chi_{2}^{2}=0.277, p=0.871\right)$ or mass-specific MS $\left(\chi_{2}^{2}=0.702, p=0.704\right.$; note $2 \mathrm{df}$ for the model comparisons as the random regression formulation includes intercept-slope covariance as well as the two variance terms). A significant positive effect of measure type (AMR relative to RMR) was found confirming the expectation that AMR should be significantly higher on average (coefficient $\left.=0.758(0.062), F_{1,106}=150.66, p \leqslant 0.001\right)$. Other fixed effect results are not directly relevant to current hypotheses but can be found in Supplemental Table 1 for completeness.

Thus we conclude that while whole animal metabolic rate varies significantly among-individuals, this can be explained by body size alone, and there is no evidence of among-individual variation in mass-specific metabolic rate 
(reaction norm height) or scope (reaction norm slope; Figure 2a). This study applies the POLS framework at the among-individual level, and amongindividual variance in metabolic traits is a prerequisite for among-individual covariance between metabolism and other traits. Consequently, metabolic traits are not included in subsequent multivariate models (we note of course that while within-individual covariance between metabolism and behaviour is still expected our data are not informative for this as metabolic rate and behaviour were not measured simultaneously).

In contrast to metabolic traits, univariate models show moderately high repeatabilities (SE in parentheses) for behavioural traits, ranging from 0.31 $(0.12)$ for tracklength to $0.46(0.11)$ for area covered, and statistically significant in all cases (Table 2). Of the OFT traits, only tracklength and area covered changed significantly over the trials with both increasing with increasing trial number (see Table A1 in the online version of this journal, which can be accessed via http://booksandjournals.brillonline.com/content/ journals/1568539x). Our univariate model of standard length confirm that fish vary significantly in size, as was obvious a priori (comparison of models with and without random fish identity effect; $\chi_{0,1}^{2}=387, p \leqslant 0.001$ ), but also growth rate (comparison of the random regression formulation including fish identity by time to a model with just fish identity; $\chi_{2}^{2}=18.5$, $p \leqslant 0.001)$. Thus, while there is a modestly positive average rate of growth (of $0.013(0.003)$ sdu/day (or $0.265 \mathrm{~mm} /$ day)) there is also significant variation around this (Figure 2b).

Multivariate models of the behavioural traits confirm significant covariance structure between behaviours at the among-individual level (comparison of full model to a reduced multivariate model in which all amongindividual covariance terms are fixed to zero; $\chi_{15}^{2}=34.5, p=0.003$ ). Post hoc testing of pairwise covariances with a series of bivariate mixed models (see Table A2 in the online version of this journal, which can be accessed via http://booksandjournals.brillonline.com/content/journals/ $1568539 \mathrm{x})$ suggests significant among-individual covariance structure is largely driven by a strong positive relationship between tracklength and activity, and strong negative relationships between these two traits and time in middle (Table 1). We note that not all pairwise correlations among behavioural traits are as expected a priori (Table 1; see discussion for full interpretation). Eigenvector decomposition of the variance-covariance matrix (see Table A3 in the online version of this journal, which can 


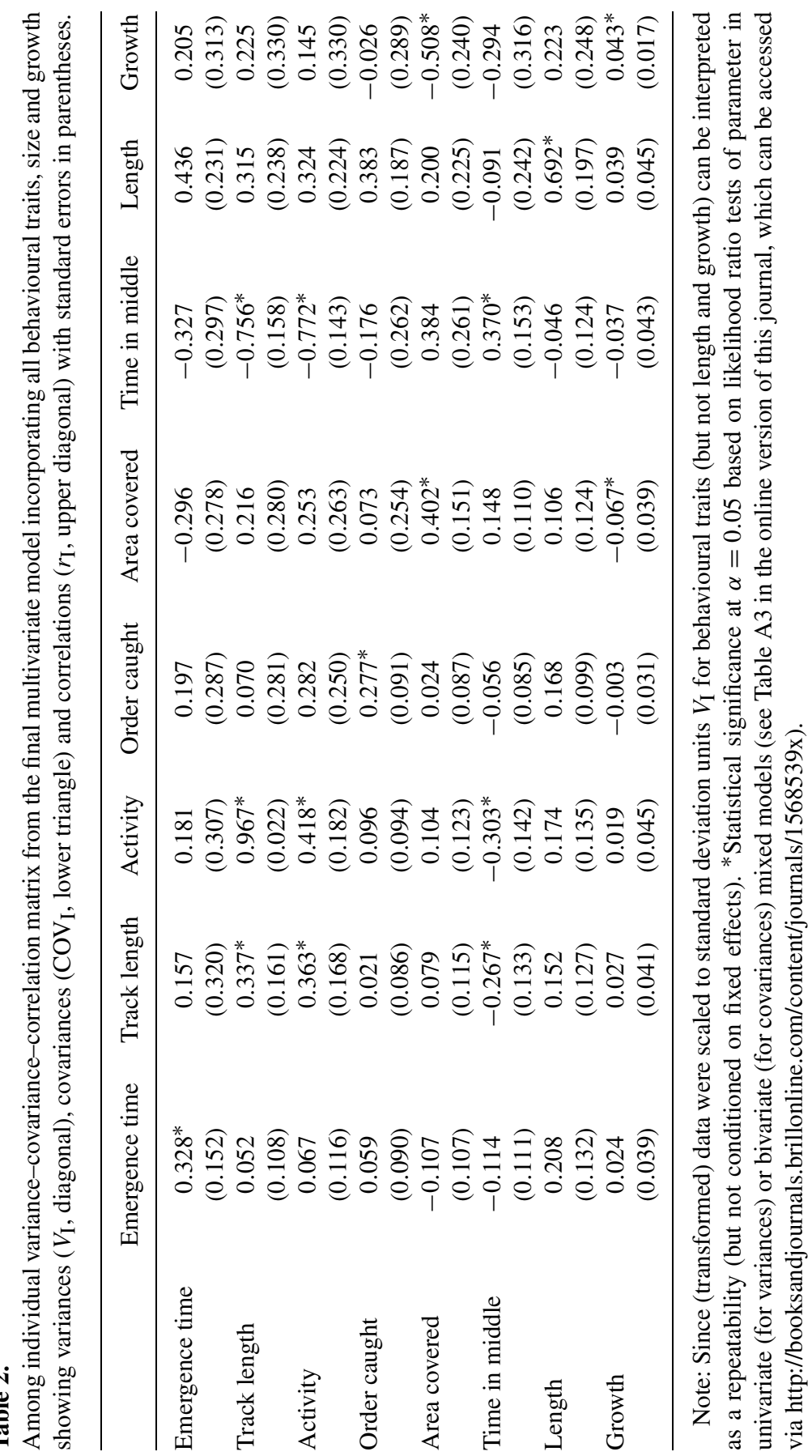



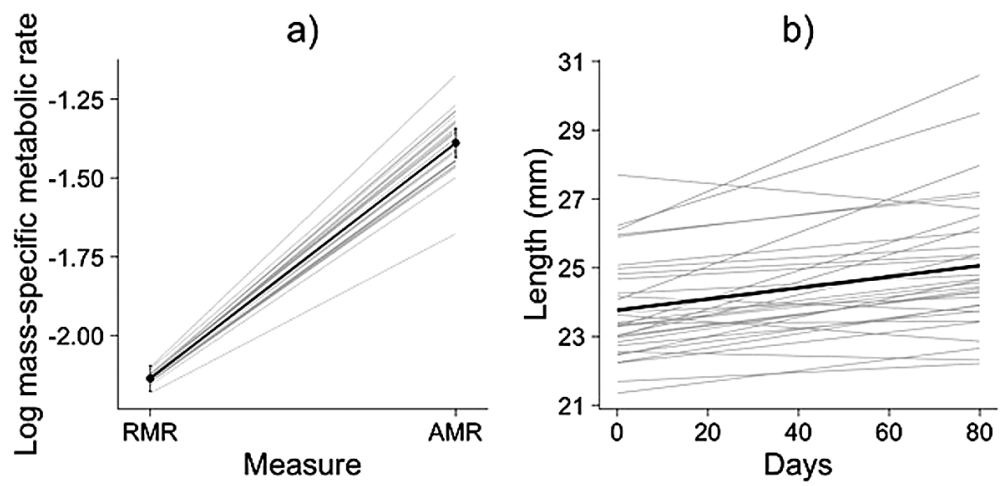

Figure 2. Metabolic traits (a) and standard length as a function days since the start of the experiment (b). Black lines show (a) the predicted mean metabolic reaction norm between activity state specific means $( \pm \mathrm{SE}$ ) and (b) mean growth trajectory. Grey lines indicate reaction norms and growth lines for each individual as predicted by the mixed model analysis.

be accessed via http://booksandjournals.brillonline.com/content/journals/ $1568539 x)$ does not clearly support our a priori expectation that amongindividual (co)variance in behavioural traits would be consistent with a single underlying personality trait. Finally, extending the multivariate model to include standard length as an additional response variable shows that, while some moderate among-individual correlations between behaviours and size were estimated, only the correlation between area covered and growth is significant $\left(\chi_{2}^{2}=6.05, p=0.048\right)$ (tested using bivariate models; Table A4 in the online version of this journal, which can be accessed via http:// booksandjournals.brillonline.com/content/journals/1568539x).

\section{Discussion}

Using a repeated measures design we tested the prediction of POLS that among-individual differences in metabolic traits (rate and scope) covary with behaviour and growth variation, with the additional prediction that it is among-individual variation in MS that drives behaviour variation. All observed behaviours tested were repeatable, consistent with the presence of underlying personality variation, and growth rate also varied significantly among-fish over the experimental period. However, after accounting for the expected increase of oxygen consumption with body size, we found no support for repeatable variation in mass specific metabolic rate or MS. Furthermore, there was little evidence of the predicted among-individual correlation 
between risky behaviour and growth rate. Thus our data are not consistent with our assertion that metabolic processes drive personality variation and we also conclude that the POLS is not supported in this population.

The lack of among-individual repeatability in metabolic traits in this study contrasts notably with other work on wild caught fish species held under laboratory conditions. For instance, mass-specific SMR has generally been reported to have moderate to high repeatabilities (e.g., $R$ ranging from 0.50 to 0.74 ) in most fish species tested under highly controlled conditions (McCarthy, 2000; Maciak \& Konarzewski, 2010; Seppänen et al., 2010; Boldsen et al., 2013; Svendsen et al., 2014). Mass-specific RMR is sometimes expected to exhibit greater variation within individuals than SMR (due to uncontrolled activity during measurement of the latter), but nonetheless is often characterised by more moderate $(R=0.3-0.6)$ repeatability (Marras et al., 2010; Killen et al., 2011, 2014). Furthermore, variable, but significant, repeatability estimates have also been reported for mass-specific MMR (e.g., $R=0.27-0.76$; McCarthy, 2000; Marras et al., 2010; Norin \& Malte, 2011; Svendsen et al., 2014; Norin et al., 2015) and MS (e.g., $R=0.39-0.43$; Norin \& Malte, 2011; Norin et al., 2015).

We note of course that measurement error could be a non-trivial source of within fish variation, and inadequate precision of respirometers can cause low repeatability of metabolic traits (Nespolo \& Franco, 2007; Careau et al., 2008). Nonetheless, we feel this is unlikely to explain the complete absence of detectable $V_{I}$ here. Firstly, within each RMR sampling assay, we averaged the three oxygen consumption slopes estimated over the $50 \mathrm{~min}$ period to reduce error as described above. However, scrutiny of these measures shows significant repeatability among slopes within-assay, even without being able to control for changing level of fish activity $\left(R=0.56, \chi_{1}^{2}=52.47, p \leqslant\right.$ 0.001 ) indicating stable performance of the instrumentation at least over the short term. Secondly, our repeated measures sampling was designed to detect repeatabilities as low as $20 \%$ (i.e., below published estimates) with high $(>75 \%)$ power (following Wilson et al., 2011b). Thirdly, we note that the experiment did in fact successfully detect among-individual variation in whole organism metabolic rate $(R=0.27)$, but that our results show this can be totally explained by differences in individual weight.

Previous studies have shown the potential role of early life conditions, including the maternal nutritional environment, in generating variation in, and correlations between putative components of POLS. For instance food 
restriction during juvenile stages can increase the repeatability of metabolic rate later in life, with individuals varying in response to nutritional stress experienced as juveniles (O'Connor et al., 2000; Careau et al., 2014a, b). The environment experienced by parents, particularly the mother, can also lead to variation between individuals in a range of traits, including adult metabolic rate (Tobler et al., 2007; Régnier et al., 2010; Burton et al., 2011; Van Leeuwen et al., 2016). In our study, the laboratory conditions experienced by fish during these important developmental windows were likely relatively homogeneous by comparison to field environments. This could have resulted in a reduction of among-individual variance in metabolic rate and scope, relative to wild caught fish used in other studies that have experienced greater patchiness of resources (Grether et al., 2001; Magurran, 2005).

Since we found no support for among-individual variation in metabolic traits, our data do not support the hypothesis that metabolism is an important determinant of individual differences in behaviour. Nonetheless, such differences are clearly present among the guppies tested, with significant repeatability found for emergence time and all OFT traits. In general, repeatabilities were of similar magnitude to those reported in the literature for behaviours generally, and in poeciliid fishes specifically (Bell et al., 2009; Cote et al., 2011; Boulton et al., 2014). We also found that, within each housing group, the order in which fish were caught was repeatable. The tendency for some individuals to be trapped or caught more easily than others has been used as a measure of boldness or risk taking behaviour. In general bolder/risk-prone individuals are more easily caught than the shy/risk-averse (Réale et al., 2000; Biro \& Sampson, 2015; Le Coeur et al., 2015; Petelle et al., 2015), consistent with the predicted consequences of this personality trait for predation risk (but see Diaz Pauli et al., 2015). Since fish in this study were actively collected (albeit haphazardly), there is an obvious possibility that some form of researcher bias that would not be exhibited by a natural predator in the field contributes to the repeatability of order caught. We note that fish tags are only clearly visible after capture, and researchers were blind to the behavioural profile data of each fish. Regardless, this finding also suggests initial sampling of experimental fish from stock tanks could itself have been selective with respect to behaviours to be studied. The possibility of samples not being fully representative of behavioural variation in 
a studied population has wider implications for personality studies (Carter et al., 2012).

The individual traits observed in OFT and emergence trials have been widely used to assay risky or bold behaviour in fishes, including guppies (Budaev, 1997; Burns, 2008; Diaz Pauli et al., 2015). However our analysis provided somewhat mixed support for our second prediction, that individuals would show (multivariate) personality variation consistent with a simple axis of variation along a risk prone-risk averse continuum. Under this model, we expected that all OFT traits would be positively correlated with each other and negatively correlated with time to emerge and capture order at the individual level. In fact, significant among-individual correlations were found only between tracklength and activity (positive as predicted) and between these two traits and time in middle. Surprisingly, time in the middle was actually negatively correlated among-individuals with the former two traits. Eigenvector decomposition of the among-individual variancecovariance matrix ('I') estimate identifies two major vectors that, together, explain $74 \%$ of the variation. The first vector, accounting for $47 \%$ of the variation, is dominated by tracklength, activity and time in the middle. The second vector, accounting for $27 \%$ of the variation, is more characterised by emergence time and area covered.

Thus the among-individual covariance structure of behavioural traits suggests that the simple model of a risk-prone risk-averse continuum is not valid in this population, and/or that it is being masked by other aspects of personality being expressed in our trials. This result differs from a study on a different poeciliid, Xiphophorus birchmanni by Boulton et al. (2014) in which strong positive correlations between the same OFT traits were found, with the 'I' matrix dominated by a single-vector interpretable as a risk averse - risk prone axis (or shy-bold). Thus an important conclusion emerging from the current behavioural data is that a particular assay or observed trait(s) may not be informative for the same personality trait in different species, even if closely related. Indeed this may also be the case for different populations of a single species. For instance, while we know that mean boldness differs among natural populations of guppies according to predation regime (Reznick et al., 1996), among-population comparisons of 'I' matrices would add considerable resolution to our understanding of where among-individual variation is maintained and how it is structured by genetic and ecological factors. In this instance, differences in the behavioural ecology between guppies 
and swordtails could contribute to differences in OFT patterns, with swordtails being more territorial relative to the shoaling, social guppy. Regardless, by measuring multiple behaviours from different tests, measures of personality can be validated rather than relying on a priori definitions of personality that may not be appropriate for a given species.

More speculatively, we consider it likely that OFT traits in this case are capturing elements of behavioural stress response or coping style (Koolhaas et al., 1999; Boulton et al., 2015), particularly as this was a 'forced' rather than voluntary trial (Huntingford, 1976; Walsh \& Cummins, 1976; Carter et al., 2013). Behavioural responses to stress in fish have been described as ranging from reactive (often characterised by freezing behaviour) to proactive (e.g., highly active fight or flight behaviour). This axis is sometimes, but not always, viewed as synonymous with variation in risky behaviour (van Raaij et al., 1996; Koolhaas et al., 1999; Brelin et al., 2005; Øverli et al., 2007; Silva et al., 2010). Here we note that video observations revealed a relatively common behavioural pattern of swimming rapidly back and forth along one side of the tank (generating high tracklength and activity, but low time in the middle). This was more consistent with expectations for a proactive coping style (i.e., active attempt to escape) rather than risky or bold behaviour as normally defined (e.g., reduced thigmotaxis, higher exploration).

A final prediction made under the POLS was that individuals with more risk-prone personalities would have higher growth rates. Even in the absence of metabolic variation as a driver, the prediction of a risky personality trait being positively associated with resource acquisition is unchanged (Stamps, 2007; Biro \& Stamps, 2008). While several studies of fish species to date have found this relationship (Ward et al., 2004; Huntingford et al., 2010; Mas-Muñoz et al., 2011), it is not supported by our data. Individuals did vary significantly in growth rate over the short term study, but only area covered showed a significant correlation with growth rate, and it was negative not positive as predicted. Given the lack of a clear risk-prone risk-averse behavioural axis it may be misleading to over-interpret this finding from a single behavioural trait (i.e., we do not conclude that risk-averse fish grow faster).

More generally we note that while a degree of social competition is expected, fish were all fed to satiation in the study. Social environments can certainly contribute to development of personality traits (Webster \& Ward, 
2011) and could also influence wider patterns of trait correlation. Thus if personality-growth correlations found elsewhere are generated by competitive advantage of, for instance, risk-prone over risk-averse individuals (Biro $\&$ Stamps, 2010; Niemelä et al., 2012), then these are expected to be stronger under conditions of resource limitation (Wilson, 2014). In contrast, relationships should be weaker under conditions that tend to equalise food intake levels between risk-prone and risk-averse individuals, such as under high resource environments.

In conclusion this study found no support for POLS in the guppy population tested. Once the dependence on body size was accounted for, we found no support for variation among-individuals in metabolic rate or scope. Thus we conclude that metabolism is not always a plausible driver of among-individual variation in behaviour. All behavioural traits chosen as putative indicators of a risk-averse/risk-prone behavioural axis were repeatable. However, the among-individual covariance structure was not actually consistent with the presence of a single underlying latent personality trait, and there was no support for the predicted association of risky behaviour with faster growth. Although we note that patterns of among-individual trait (co)variation are certainly expected to show environmental sensitivity, our behavioural results highlight the value of multivariate (i.e., multiple trait and multiple trial type) repeated measures data. In seeking to test mechanistic explanations for the maintenance of animal personality it is important that we have an understanding of how behavioural variation is actually structured among-individuals in the focal population (i.e., to what extent do individual behaviours provide information about personality axes that are generalizable over population or species). This is particularly important in POLS research where the expectation of positive correlations between behaviour, physiology and growth may be dependent on access to resources, territory or mates.

Finally, we stress that while among-individual (co)variation provides the raw material upon which selection can act, it is the structure of genetic (co)variation that will determine how traits such as personality evolve, and coevolve, under selection. Others have found abundant evidence for heritable variation underpinning personality (van Oers et al., 2005; Dingemanse et al., 2012; Oswald et al., 2013), though tests of genetic (co)variance structures remain limited. While we found no support here for POLS at the level of the individual phenotype, we suggest that quantitative genetic studies to test for and characterise genetic integration of behaviour, physiology and life 
history traits would provide a useful route to understanding the evolution of personality.

\section{Acknowledgements}

We would like to thank Lucy Hawkes and Shaun Killen for advice on the metabolic procedure, Tom Houslay and three anonymous reviewers for useful comments on the manuscript, and Andrew Grimmer for technical expertise. Funding was provided by a Natural Environment Research Council PhD studentship to SJW and by a grant from the Biotechnology and Biological Sciences Research Council (BB/L022656/1).

\section{References}

Bell, A.M., Hankison, S.J. \& Laskowski, K.L. (2009). The repeatability of behaviour: a metaanalysis. - Anim. Behav. 77: 771-783.

Biro, P.A. \& Sampson, P. (2015). Fishing directly selects on growth rate via behaviour: implications of growth-selection that is independent of size. - Proc. Roy. Soc. Lond. B: Biol. Sci. 282: 13-15.

Biro, P.A. \& Stamps, J.A. (2008). Are animal personality traits linked to life-history productivity? - Trends Ecol. Evol. 23: 361-368.

Biro, P.A. \& Stamps, J.A. (2010). Do consistent individual differences in metabolic rate promote consistent individual differences in behavior? - Trends Ecol. Evol. 25: 653659.

Boldsen, M.M., Norin, T. \& Malte, H. (2013). Temporal repeatability of metabolic rate and the effect of organ mass and enzyme activity on metabolism in European eel (Anguilla anguilla). — Comp. Biochem. Physiol. A: Mol. Integr. Physiol. 165: 22-29.

Boulton, K., Grimmer, A.J., Rosenthal, G.G., Walling, C.A. \& Wilson, A.J. (2014). How stable are personalities? A multivariate view of behavioural variation over long and short timescales in the sheepshead swordtail, Xiphophorus birchmanni. - Behav. Ecol. Sociobiol. 68: 791-803.

Boulton, K., Couto, E., Grimmer, A.J., Earley, R.L., Canario, A.V.M., Wilson, A.J. \& Walling, C.A. (2015). How integrated are behavioral and endocrine stress response traits? A repeated measures approach to testing the stress-coping style model. — Ecol. Evol. 5: 618-633.

Bouwhuis, S., Quinn, J.L., Sheldon, B.C. \& Verhulst, S. (2014). Personality and basal metabolic rate in a wild bird population. - Oikos 123: 56-62.

Brelin, D., Petersson, E. \& Winberg, S. (2005). Divergent stress coping styles in juvenile brown trout (Salmo trutta). — Ann. N.Y. Acad. Sci. 1040: 239-245.

Briffa, M., Sneddon, L.U. \& Wilson, A.J. (2015). Animal personality as a cause and consequence of contest behaviour. - Biol. Lett. 11(3): 20141007. 
Bronikowski, A., Clark, M.E., Rodd, F.H. \& Reznick, D.N. (2002). Population-dynamic consequences of predator-induced life history variation in the guppy (Poecilla reticulata). — Ecology 83: 2194-2204.

Budaev, S.V. (1997). "Personality" in the guppy (Poecilia reticulata): a correlational study of exploratory behavior and social tendency. — J. Comp. Psychol. 111: 399-411.

Burns, J.G. (2008). The validity of three tests of temperament in guppies (Poecilia reticulata). - J. Comp. Psychol. 122: 344-356.

Burton, T., Killen, S.S., Armstrong, J.D. \& Metcalfe, N.B. (2011). What causes intraspecific variation in resting metabolic rate and what are its ecological consequences? - Proc. Roy. Soc. Lond. B: Biol. Sci. 278: 3465-3473.

Careau, V., Buttemer, W.A. \& Buchanan, K.L. (2014a). Early-developmental stress, repeatability, and canalization in a suite of physiological and behavioral traits in female zebra finches. - Integr. Comp. Biol. 54: 1-16.

Careau, V., Buttemer, W.A. \& Buchanan, K.L. (2014b). Developmental stress can uncouple relationships between physiology and behaviour. — Biol. Lett. 10: 20140834.

Careau, V. \& Garland, T. (2012). Performance, personality, and energetics: correlation, causation, and mechanism. - Physiol. Biochem. Zool. 85: 543-571.

Careau, V., Montiglio, P.-O., Garant, D., Pelletier, F., Speakman, J.R., Humphries, M.M. \& Réale, D. (2015). Energy expenditure and personality in wild chipmunks. - Behav. Ecol. Sociobiol. 69: 653-661.

Careau, V., Réale, D., Garant, D., Pelletier, F., Speakman, J.R. \& Humphries, M.M. (2013). Context-dependent correlation between resting metabolic rate and daily energy expenditure in wild chipmunks. - J. Exp. Biol. 216: 418-426.

Careau, V., Réale, D., Humphries, M.M. \& Thomas, D.W. (2010). The pace of life under artificial selection: personality, energy expenditure, and longevity are correlated in domestic dogs. - Am. Nat. 175: 753-758.

Careau, V., Thomas, D., Humphries, M.M. \& Re, D. (2008). Energy metabolism and animal personality. - Oikos 117: 641-653.

Carter, A.J., Feeney, W.E., Marshall, H.H., Cowlishaw, G. \& Heinsohn, R. (2013). Animal personality: what are behavioural ecologists measuring? - Biol. Rev. 88: 465-475.

Carter, A.J., Heinsohn, R., Goldizen, A.W. \& Biro, P.A. (2012). Boldness, trappability and sampling bias in wild lizards. - Anim. Behav. 83: 1051-1058.

Cote, J., Fogarty, S., Brodin, T., Weinersmith, K. \& Sih, A. (2011). Personality-dependent dispersal in the invasive mosquitofish: group composition matters. - Proc. Roy. Soc. Lond. B: Biol. Sci. 278: 1670-1678.

Croft, D.P., Krause, J. \& James, R. (2004). Ocial networks in the guppy (Poecilia reticulata). — Proc. Roy. Soc. Lond. B: Biol. Sci. 271: 516-519.

Cutts, C.J., Metcalfe, N.B. \& Taylor, A.C. (2002). Juvenile Atlantic salmon (Salmo salar) with relatively high metabolic rates have small metabolic scopes. — Funct. Ecol. 16: 7378.

Diaz Pauli, B., Wiech, M., Heino, M. \& Utne-Palm, A.C. (2015). Opposite selection on behavioural types by active and passive fishing gears in a simulated guppy Poecilia reticulata fishery. - J. Fish Biol. 86: 1030-1045. 
Dingemanse, N.J., Kazem, A.J.N., Réale, D. \& Wright, J. (2010). Behavioural reaction norms: animal personality meets individual plasticity. — Trends Ecol. Evol. 25: 81-89.

Dingemanse, N.J., Barber, I., Wright, J. \& Brommer, J.E. (2012). Quantitative genetics of behavioural reaction norms: genetic correlations between personality and behavioural plasticity vary across stickleback populations. - J. Evol. Biol. 25: 485-496.

Finstad, A.G., Forseth, T., Ugedal, O. \& Naesje, T.F. (2007). Metabolic rate, behaviour and winter performance in juvenile Atlantic salmon. — Funct. Ecol. 21: 905-912.

Gifford, M.E., Clay, T.A. \& Careau, V. (2014). Individual (co)variation in standard metabolic rate, feeding rate, and exploratory behavior in wild-caught semiaquatic salamanders. Physiol. Biochem. Zool. 87: 384-396.

Grether, G.F., Millie, D.F., Bryant, M.J., Reznick, D.N. \& Mayea, W. (2001). Rain forest canopy cover, resource availability, and life history evolution in guppies. - Ecology 82: 1546-1559.

Hansen, S.L. \& Hunt Von Herbing, I. (2009). Aerobic scope for activity in age 0 year Atlantic cod Gadus morhua. — J. Fish Biol. 74: 1355-1370.

Harris, S., Ramnarine, I.W., Smith, H.G. \& Pettersson, L.B. (2010). Picking personalities apart: estimating the influence of predation, sex and body size on boldness in the guppy Poecilia reticulata. - Oikos 119: 1711-1718.

Hohn, C. \& Petrie-Hanson, L. (2013). Evaluation of visible implant elastomer tags in zebrafish (Danio rerio). — Biol. Open 2: 1397-1401.

Huntingford, F.A. (1976). The relationship between anti-predator behaviour and aggression among conspecifics in the three-spined stickleback, Gasterosteus aculeatus. - Anim. Behav. 24: 245-260.

Huntingford, F.A., Andrew, G., Mackenzie, S., Morera, D., Coyle, S.M., Pilarczyk, M. \& Kadri, S. (2010). Coping strategies in a strongly schooling fish, the common carp Cyprinus carpio. - J. Fish Biol. 76: 1576-1591.

Killen, S.S., Marras, S. \& McKenzie, D.J. (2011). Fuel, fasting, fear: routine metabolic rate and food deprivation exert synergistic effects on risk-taking in individual juvenile European sea bass. - J. Anim. Ecol. 80: 1024-1033.

Killen, S.S., Marras, S., Ryan, M.R., Domenici, P. \& McKenzie, D.J. (2012). A relationship between metabolic rate and risk-taking behaviour is revealed during hypoxia in juvenile European sea bass. - Funct. Ecol. 26: 134-143.

Killen, S.S., Mitchell, M.D., Rummer, J.L., Chivers, D.P., Ferrari, M.C.O., Meekan, M.G. \& Mccormick, M.I. (2014). Aerobic scope predicts dominance during early life in a tropical damselfish. - Funct. Ecol.: 1367-1376.

Koolhaas, J.M., Korte, S.M., De Boer, S.F., Van Der Vegt, B.J., Van Reenen, C.G., Hopster, H., De Jong, I.C., Ruis, M.A.W. \& Blokhuis, H.J. (1999). Coping styles in animals: current status in behavior and stress-physiology. — Neurosci. Biobehav. Rev. 23: 925-935.

Lantová, P., Zub, K., Koskela, E., Šíchová, K. \& Borowski, Z. (2011). Is there a linkage between metabolism and personality in small mammals? The root vole (Microtus oeconomus) example. - Physiol. Behav. 104: 378-383. 
Le Coeur, C., Thibault, M., Pisanu, B., Thibault, S., Chapuis, J.L. \& Baudry, E. (2015). Temporally fluctuating selection on a personality trait in a wild rodent population. Behav. Ecol. 26: 1285-1291.

Le Galliard, J.-F., Paquet, M., Cisel, M. \& Montes-Poloni, L. (2013). Personality and the pace-of-life syndrome: variation and selection on exploration, metabolism and locomotor performances. - Funct. Ecol. 27: 136-144.

Maciak, S. \& Konarzewski, M. (2010). Repeatability of standard metabolic rate (SMR) in a small fish, the spined loach (Cobitis taenia). — Comp. Biochem. Physiol. — A Mol. Integr. Physiol. 157: 136-141.

Magurran, A.E. (2005). Evolutionary ecology: the Trinidadian guppy. — Oxford University Press, Oxford.

Marras, S., Claireaux, G., McKenzie, D.J. \& Nelson, J.A. (2010). Individual variation and repeatability in aerobic and anaerobic swimming performance of European sea bass, Dicentrarchus labrax. - J. Exp. Biol. 213: 26-32.

Martin, L.B., Hasselquist, D. \& Wikelski, M. (2006). Investment in immune defense is linked to pace of life in house sparrows. - Oecologia 147: 565-575.

Mas-Muñoz, J., Komen, H., Schneider, O., Visch, S.W. \& Schrama, J.W. (2011). Feeding behaviour, swimming activity and boldness explain variation in feed intake and growth of sole (Solea solea) reared in captivity. — PLoS ONE 6: e21393.

Mathot, K.J. \& Dingemanse, N.J. (2015). Energetics and behavior: unrequited needs and new directions. - Trends Ecol. Evol. 30: 199-206.

Mathot, K.J., Nicolaus, M., Araya-Ajoy, Y.G., Dingemanse, N.J. \& Kempenaers, B. (2014). Does metabolic rate predict risk-taking behaviour? A field experiment in a wild passerine bird. - Funct. Ecol. 29: 239-249.

McCarthy, I.D. (2001). Competitive ability is related to metabolic asymmetry in juvenile rainbow trout. — J. Fish Biol. 59: 1002-1014.

McCarthy, I.D. (2000). Temporal repeatability of relative standard metabolic rate in juvenile Atlantic salmon and its relation to life history variation. - J. Fish Biol. 57: 224-238.

Metcalfe, N.B., Van Leeuwen, T.E. \& Killen, S.S. (2015). Does individual variation in metabolic phenotype predict fish behaviour and performance? - J. Fish Biol. 88: 298321.

Møller, A.P. (2009). Basal metabolic rate and risk-taking behaviour in birds. — J. Evol. Biol. 22: $2420-2429$.

Nakagawa, S. \& Schielzeth, H. (2010). Repeatability for Gaussian and non-Gaussian data: a practical guide for biologists. - Biol. Rev. 85: 935-956.

Nespolo, R.F. \& Franco, M. (2007). Whole-animal metabolic rate is a repeatable trait: a metaanalysis. — J. Exp. Biol. 210: 2000-2005.

Niemelä, P.T., Vainikka, A., Hedrick, A.V. \& Kortet, R. (2012). Integrating behaviour with life history: boldness of the field cricket, Gryllus integer, during ontogeny. — Funct. Ecol. 26: 450-456.

Norin, T. \& Malte, H. (2011). Repeatability of standard metabolic rate, active metabolic rate and aerobic scope in young brown trout during a period of moderate food availability. J. Exp. Biol. 214: 1668-1675. 
Norin, T., Malte, H. \& Clark, T.D. (2016). Differential plasticity of metabolic rate phenotypes in a tropical fish facing environmental change. - Funct. Ecol. 30: 369-378.

Nussey, D.H., Wilson, A.J. \& Brommer, J.E. (2007). The evolutionary ecology of individual phenotypic plasticity in wild populations. - J. Evol. Biol. 20: 831-844.

O’Connor, K.I., Taylor, A.C. \& Metcalfe, N.B. (2000). The stability of standard metabolic rate during a period of food deprivation in juvenile Atlantic salmon. - J. Fish Biol. 57: 41-51.

Oswald, M.E., Singer, M. \& Robison, B.D. (2013). The quantitative genetic architecture of the bold-shy continuum in zebrafish, Danio rerio. — PLoS ONE 8: e68828.

Øverli, Ø., Sørensen, C., Pulman, K.G.T., Pottinger, T.G., Korzan, W., Summers, C.H. \& Nilsson, G.E. (2007). Evolutionary background for stress-coping styles: relationships between physiological, behavioral, and cognitive traits in non-mammalian vertebrates. Neurosci. Biobehav. Rev. 31: 396-412.

Petelle, M.B., Martin, J.G.A. \& Blumstein, D.T. (2015). Heritability and genetic correlations of personality traits in a wild population of yellow-bellied marmots (Marmota flaviventris). - J. Evol. Biol. 28: 1840-1848.

Previtali, M.A., Ostfeld, R.S., Keesing, F., Jolles, A.E., Hanselmann, R. \& Martin, L.B. (2012). Relationship between pace of life and immune responses in wild rodents. - Oikos 121: 1483-1492.

Réale, D., Gallant, B., Leblanc, M. \& Festa-Bianchet, M. (2000). Consistency of temperament in bighorn ewes and correlates with behaviour and life history. - Anim. Behav. 60: 589-597.

Réale, D., Garant, D., Humphries, M.M., Bergeron, P., Careau, V. \& Montiglio, P.-O. (2010). Personality and the emergence of the pace-of-life syndrome concept at the population level. — Philos. Trans. Roy. Soc. Lond. B: Biol. Sci. 365: 4051-4063.

Régnier, T., Bolliet, V., Labonne, J. \& Gaudin, P. (2010). Assessing maternal effects on metabolic rate dynamics along early development in brown trout (Salmo trutta): an individual-based approach. - J. Comp. Physiol. B: Biochem. Syst. Environ. Physiol. 180: 25-31.

Reznick, D.N., Rodd, F.H. \& Cardenas, M. (1996). Life-history evolution in guppies (Poecilia reticulata: Poeciliidae). IV. Parallelism in life-history phenotypes. - Am. Nat. 147: 319338.

Ricklefs, R.E. \& Wikelski, M. (2002). The physiology/life-history nexus. — Trends Ecol. Evol. 17: 462-468.

Robertsen, G., Armstrong, J.D., Nislow, K.H., Herfindal, I., McKelvey, S. \& Einum, S. (2013). Spatial variation in the relationship between performance and metabolic rate in wild juvenile Atlantic salmon. - J. Anim. Ecol.: 791-799.

Roff, D.A. \& Wilson, A.J. (2014). Quantifying genotype-by-environment interactions in laboratory systems. - In: Genotype-by-environment interactions and sexual selection (Hunt, J. \& Hosken, D., eds). Wiley, Chichester, p. 101-136.

Russell, G.A. \& Chappell, M.A. (2007). Is BMR repeatable in deer mice? Organ mass correlates and the effects of cold acclimation and natal altitude. - J. Comp. Physiol. B Biochem. Syst. Environ. Physiol. 177: 75-87. 
Seppänen, E., Piironen, J. \& Huuskonen, H. (2010). Consistency of standard metabolic rate in relation to life history strategy of juvenile Atlantic salmon Salmo salar. - Comp. Biochem. Physiol. A: Mol. Integr. Physiol. 156: 278-284.

Silva, P.I.M., Martins, C.I.M., Engrola, S., Marino, G., Øverli, Ø. \& Conceição, L.E.C. (2010). Individual differences in cortisol levels and behaviour of Senegalese sole (Solea senegalensis) juveniles: evidence for coping styles. — Appl. Anim. Behav. Sci. 124: 7581.

Speakman, J.R., Ergon, T., Cavanagh, R., Reid, K., Scantlebury, D.M. \& Lambin, X. (2003). Resting and daily energy expenditures of free-living field voles are positively correlated but reflect extrinsic rather than intrinsic effects. — Proc. Natl. Acad. Sci. 100: 1405714062.

Stamps, J.A. (2007). Growth-mortality tradeoffs and "personality traits" in animals. — Ecol. Lett. 10: 355-363.

Svendsen, J.C., Genz, J., Anderson, W.G., Stol, J.A., Watkinson, D.A. \& Enders, E.C. (2014). Evidence of circadian rhythm, oxygen regulation capacity, metabolic repeatability and positive correlations between forced and spontaneous maximal metabolic rates in lake sturgeon Acipenser fulvescens. — PLoS ONE 9: e94693.

Tobler, M., Nilsson, J.-K. \& Nilsson, J.F. (2007). Costly steroids: egg testosterone modulates nestling metabolic rate in the zebra finch. - Biol. Lett. 3: 408-410.

Van Leeuwen, T.E., McLennan, D., McKelvey, S., Stewart, D.C., Adams, C.E. \& Metcalfe, N.B. (2016). The association between parental life history and offspring phenotype. J. Exp. Biol. 219: 374-382.

van Oers, K., de Jong, G., van Noordwijk, A. \& Drent, P.J. (2005). Contribution of genetics to the study of animal personalities: a review of case studies. - Behaviour 142: 1185-1206.

van Raaij, M.T., Pit, D.S., Balm, P.H., Steffens, A.B. \& van den Thillart, G.E. (1996). Behavioral strategy and the physiological stress response in rainbow trout exposed to severe hypoxia. - Horm. Behav. 30: 85-92.

Visscher, P.M. (2006). A note on the asymptotic distribution of likelihood ratio tests to test variance components. — Twin Res. Hum. Genet. 9: 490-495.

Walsh, R.N. \& Cummins, R.A. (1976). The open-field test: a critical review. — Psychol. Bull. 83: 482-504.

Ward, A.J.W., Thomas, P., Hart, P.J.B. \& Krause, J. (2004). Correlates of boldness in threespined sticklebacks (Gasterosteus aculeatus). — Behav. Ecol. Sociobiol. 55: 561-568.

Webster, M.M. \& Ward, A.J.W. (2011). Personality and social context. - Biol. Rev. 86: 759-773.

Wiersma, P., Muñoz-Garcia, A., Walker, A. \& Williams, J.B. (2007). Tropical birds have a slow pace of life. - Proc. Natl. Acad. Sci. USA 104: 9340-9345.

Wiersma, P., Nowak, B. \& Williams, J.B. (2012). Small organ size contributes to the slow pace of life in tropical birds. - J. Exp. Biol. 215: 1662-1669.

Williams, J.B., Miller, R.A., Harper, J.M. \& Wiersma, P. (2010). Functional linkages for the pace of life, life-history, and environment in birds. — Integr. Comp. Biol. 50: 855-868.

Wilson, A.J. (2014). Competition as a source of constraint on life history evolution in natural populations. - Heredity 112: 70-78. 
Wilson, A.J., de Boer, M., Arnott, G. \& Grimmer, A. (2011a). Integrating personality research and animal contes theory: aggressiveness in the green swordtail Xiphophorus helleri. PLoS ONE 6: e28024.

Wilson, A.J., Morrissey, M.B., Adams, M.J., Walling, C.A., Guinness, F.E., Pemberton, J.M., Clutton-Brock, T.H. \& Kruuk, L.E.B. (2011b). Indirect genetic effects and evolutionary constraint: an analysis of social dominance in red deer, Cervus elaphus. - J. Evol. Biol. 24: 772-783.

Wolf, M., van Doorn, G.S., Leimar, O. \& Weissing, F.J. (2007). Life-history trade-offs favour the evolution of animal personalities. — Nature 447: 581-584.

\section{Appendix}

\section{Metabolic rate estimation}

A pump was used to deliver water from the water bath through to the respiration chamber past the optical dissolved oxygen (DO) probe and back into the water bath, in what is termed the 'flush' state. For oxygen consumption measures to take place the system was switched to a 'closed' state in which water only flowed between the pump, respiration chamber and DO probe (see Figure A1), reverting back to the flush state upon completion of the measurement. This allows precise measurement of oxygen consumption

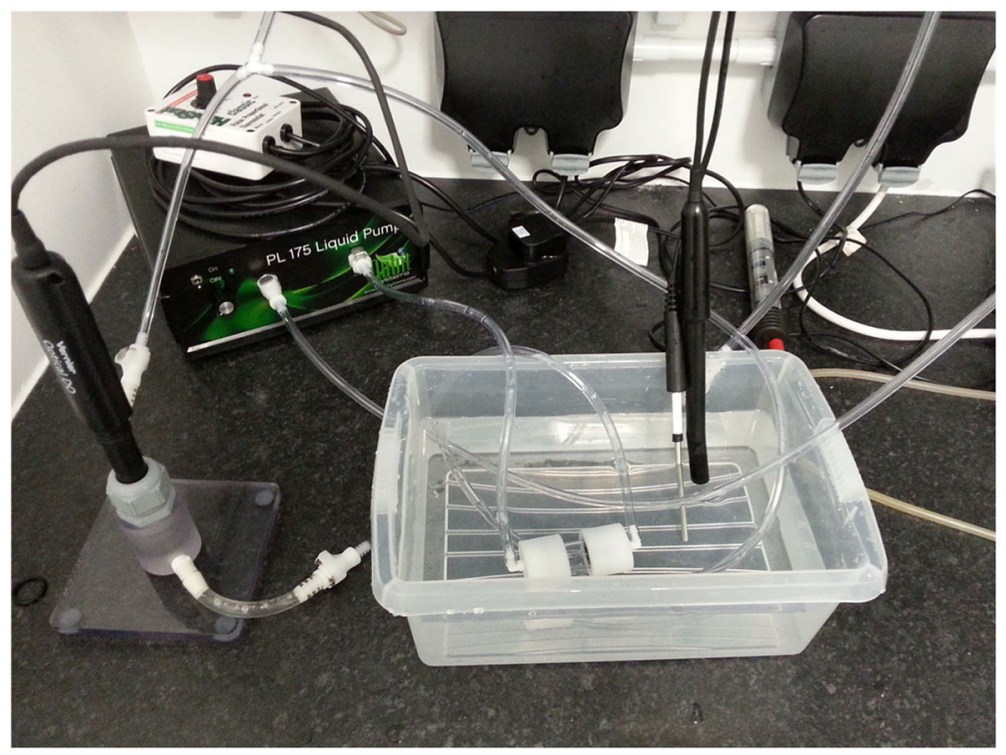

Figure A1. Experimental setup for metabolic rate estimation. 
while preventing the build-up of $\mathrm{CO}_{2}$ and other waste products in the respiration chamber.

To account for bacterial respiration in the system, oxygen consumption of the empty respiration chamber was taken either before or after each fish measure and subtracted from corresponding fish metabolic rate measures. Finally, the fish volume relative to the system volume was corrected to produce whole animal metabolic rate in $\mathrm{mg} \mathrm{O}_{2} / \mathrm{h}$ :

$$
V_{\mathrm{O}_{2}}=\text { DOslope } *\left(\mathrm{Vol}_{\mathrm{R}}-\mathrm{Vol}_{\mathrm{A}}\right) * 3600,
$$

where $V_{\mathrm{O}_{2}}$ is the oxygen consumption rate $\left(\mathrm{mg} \mathrm{O}_{2} / \mathrm{h}\right)$, DO slope is the rate of decrease of dissolved oxygen ( $\mathrm{mg} \mathrm{O}_{2} / \mathrm{l} \mathrm{per} \mathrm{s}$ ), $\mathrm{Vol}_{\mathrm{R}}$ is the volume of the active respirometer in litres $(0.069 \mathrm{l})$ and $\mathrm{Vol}_{\mathrm{A}}$ is the volume of the fish (also in 1). Tables A1-A4 show the results of the experiements.

Table A1.

Fixed effect estimates from univariate models of metabolic rate, all behaviours assayed and standard length (see main text for details).

\begin{tabular}{|c|c|c|c|c|c|c|}
\hline Trait & Fixed effect & Level & Effect size (SE) & $\mathrm{df}$ & $F$ & $P$ \\
\hline \multirow[t]{14}{*}{ Emergence } & Mean & & $-0.279(3.378)$ & $1,73.9$ & 0.01 & 0.919 \\
\hline & Temp & & $0.001(0.142)$ & $1,74.1$ & 0.00 & 0.992 \\
\hline & \multirow[t]{3}{*}{ Group } & Group 2 & $0.076(0.387)$ & \multirow[t]{3}{*}{$3,25.2$} & \multirow[t]{3}{*}{0.72} & \multirow[t]{3}{*}{0.550} \\
\hline & & Group 3 & $0.303(0.401)$ & & & \\
\hline & & Group 4 & $0.484(0.366)$ & & & \\
\hline & \multirow[t]{7}{*}{ Order caught } & 1 & $0.588(0.372)$ & \multirow[t]{7}{*}{$7,87.7$} & \multirow[t]{7}{*}{1.06} & \multirow[t]{7}{*}{0.397} \\
\hline & & 2 & $0.770(0.369)$ & & & \\
\hline & & 3 & $0.566(0.368)$ & & & \\
\hline & & 4 & $0.828(0.376)$ & & & \\
\hline & & 5 & $0.511(0.381)$ & & & \\
\hline & & 7 & $0.502(0.424)$ & & & \\
\hline & & 8 & $1.026(0.497)$ & & & \\
\hline & Trial & & $-0.041(0.027)$ & $1,74.6$ & 2.29 & 0.137 \\
\hline & Weight & & $0.197(0.449)$ & $1,61.9$ & 0.19 & 0.656 \\
\hline \multirow[t]{7}{*}{ Track length } & Mean & & $2.205(6.664)$ & $1,71.7$ & 1.57 & 0.218 \\
\hline & Temp & & $-0.042(0.289)$ & $1,71.7$ & 0.02 & 0.880 \\
\hline & \multirow[t]{3}{*}{ Group } & Group 2 & $-0.214(0.352)$ & \multirow[t]{3}{*}{$3,23.8$} & \multirow[t]{3}{*}{2.18} & \multirow[t]{3}{*}{0.118} \\
\hline & & Group 3 & $-0.214(0.351)$ & & & \\
\hline & & Group 4 & $0.548(0.344)$ & & & \\
\hline & \multirow[t]{2}{*}{ Order caught } & 1 & $-0.597(0.362)$ & \multirow[t]{2}{*}{$7,87.2$} & \multirow[t]{2}{*}{1.21} & \multirow[t]{2}{*}{0.304} \\
\hline & & 2 & $-0.738(0.351)$ & & & \\
\hline
\end{tabular}


Table A1.

(Continued.)

\begin{tabular}{|c|c|c|c|c|c|c|}
\hline Trait & Fixed effect & Level & Effect size (SE) & $\mathrm{df}$ & $F$ & $P$ \\
\hline & & 3 & $-0.055(0.340)$ & & & \\
\hline & & 4 & $-0.194(0.339)$ & & & \\
\hline & & 5 & $-0.493(0.333)$ & & & \\
\hline & & 7 & $-0.144(0.368)$ & & & \\
\hline & & 8 & $-0.111(0.419)$ & & & \\
\hline & Trial & & $0.050(0.025)$ & $1,78.2$ & 3.92 & 0.053 \\
\hline & Weight & & $1.064(0.385)$ & 1,76 & 7.65 & 0.008 \\
\hline \multirow[t]{14}{*}{ Activity } & Mean & & $1.846(6.498)$ & $1,70.8$ & 1.34 & 0.253 \\
\hline & Temp & & $-0.019(0.283)$ & $1,70.8$ & 0.00 & 0.941 \\
\hline & Group & Group 2 & $-0.288(0.369)$ & $3,24.1$ & 1.92 & 0.154 \\
\hline & & Group 3 & $-0.346(0.369)$ & & & \\
\hline & & Group 4 & $0.435(0.363)$ & & & \\
\hline & Order caught & 1 & $-0.655(0.354)$ & $7,85.2$ & 1.59 & 0.150 \\
\hline & & 2 & $-0.865(0.345)$ & & & \\
\hline & & 3 & $-0.066(0.335)$ & & & \\
\hline & & 4 & $-0.272(0.334)$ & & & \\
\hline & & 5 & $-0.573(0.327)$ & & & \\
\hline & & 7 & $-0.302(0.363)$ & & & \\
\hline & & 8 & $-0.178(0.412)$ & & & \\
\hline & Trial & & $0.032(0.025)$ & $1,77.3$ & 1.64 & 0.207 \\
\hline & Weight & & $0.983(0.388)$ & 1,81 & 6.41 & 0.014 \\
\hline \multirow[t]{6}{*}{ Order caught } & Mean & & $0.198(0.349)$ & $1,26.4$ & 0.13 & 0.726 \\
\hline & Group & Group 2 & $-0.096(0.295)$ & $3,26.9$ & 0.30 & 0.822 \\
\hline & & Group 3 & $-0.237(0.297)$ & & & \\
\hline & & Group 4 & $0.017(0.292)$ & & & \\
\hline & Trial & & $-0.052(0.013)$ & 1,425 & 17.39 & $<0.001$ \\
\hline & Weight & & $-0.202(0.263)$ & 1,201 & 0.59 & 0.443 \\
\hline \multirow[t]{12}{*}{ Area covered } & Mean & & $17.78(5.822)$ & $1,72.2$ & 2.53 & 0.119 \\
\hline & Temp & & $-0.747(0.253)$ & $1,72.2$ & 8.72 & 0.004 \\
\hline & Group & Group 2 & $0.067(0.375)$ & $3,27.1$ & 0.41 & 0.750 \\
\hline & & Group 3 & $-0.298(0.375)$ & & & \\
\hline & & Group 4 & $0.053(0.369)$ & & & \\
\hline & Order caught & 1 & $0.043(0.319)$ & $7,83.5$ & 3.64 & 0.002 \\
\hline & & 2 & $-0.069(0.313)$ & & & \\
\hline & & 3 & $-0.098(0.303)$ & & & \\
\hline & & 4 & $-0.594(0.303)$ & & & \\
\hline & & 5 & $-0.628(0.295)$ & & & \\
\hline & & 7 & $-1.188(0.331)$ & & & \\
\hline & & 8 & $-1.186(0.372)$ & & & \\
\hline
\end{tabular}


Table A1.

(Continued.)

\begin{tabular}{|c|c|c|c|c|c|c|}
\hline Trait & Fixed effect & Level & Effect size (SE) & df & $F$ & $P$ \\
\hline & Trial & & $0.081(0.022)$ & $1,77.9$ & 13.19 & $<0.001$ \\
\hline & Weight & & $0.280(0.366)$ & $1,89.1$ & 0.59 & 0.445 \\
\hline \multirow[t]{14}{*}{ Time in middle } & Mean & & $-0.517(5.91)$ & 1,71 & 1.65 & 0.205 \\
\hline & Temp & & $-0.025(0.257)$ & 1,71 & 0.01 & 0.919 \\
\hline & Group & Group 2 & $0.616(0.362)$ & $3,25.2$ & 1.99 & 0.142 \\
\hline & & Group 3 & $0.461(0.362)$ & & & \\
\hline & & Group 4 & $-0.128(0.356)$ & & & \\
\hline & Order caught & 1 & $0.142(0.323)$ & $7,83.8$ & 1.95 & 0.072 \\
\hline & & 2 & $0.307(0.317)$ & & & \\
\hline & & 3 & $-0.449(0.306)$ & & & \\
\hline & & 4 & $-0.287(0.306)$ & & & \\
\hline & & 5 & $-0.085(0.298)$ & & & \\
\hline & & 7 & $-0.570(0.334)$ & & & \\
\hline & & 8 & $-0.729(0.377)$ & & & \\
\hline & Trial & & $0.021(0.227)$ & $1,77.2$ & 0.89 & 0.349 \\
\hline & Weight & & $-0.788(0.364)$ & 1,86 & 4.69 & 0.035 \\
\hline \multirow[t]{6}{*}{ Length } & Mean & & $-0.722(0.578)$ & & & \\
\hline & Group & Group 2 & $-0.112(0.437)$ & & & \\
\hline & & Group 3 & $0.339(0.455)$ & & & \\
\hline & & Group 4 & $-0.254(0.422)$ & & & \\
\hline & Last day & & $0.012(0.007)$ & & & \\
\hline & Days since start & & $0.167(0.502)$ & & & \\
\hline \multirow{14}{*}{$\begin{array}{l}\text { Mass-specific } \\
\text { metabolic rate }\end{array}$} & Mean & & $-0.668(0.175)$ & 1,106 & 18.71 & $<0.001$ \\
\hline & Measure type & & $0.748(0.058)$ & 1,106 & 163.85 & $<0.001$ \\
\hline & Group & Group 2 & $0.049(0.840)$ & 3,106 & 0.22 & 0.884 \\
\hline & & Group 3 & $0.035(0.084)$ & & & \\
\hline & & Group 4 & $0.639(0.082)$ & & & \\
\hline & Order caught & 1 & $-0.077(0.112)$ & & & \\
\hline & & 2 & $-0.025(0.113)$ & & & \\
\hline & & 3 & $-0.106(0.114)$ & & & \\
\hline & & 4 & $0.731(0.116)$ & & & \\
\hline & & 5 & $-0.163(0.115)$ & & & \\
\hline & & 7 & $0.133(0.124)$ & & & \\
\hline & & 8 & $0.052(0.127)$ & & & \\
\hline & Trial & & $-0.005(0.127)$ & 1,106 & 0.18 & 0.664 \\
\hline & Weight & & $0.929(0.129)$ & 1,106 & 51.17 & $<0.001$ \\
\hline
\end{tabular}


Table A2.

Statistical inference among-individual covariance estimates between behavioural traits.

\begin{tabular}{llcc}
\hline Trait 1 & Trait 2 & $\chi_{1}^{2}$ & $P$ \\
\hline Track length & Order caught & 0.028 & 0.867 \\
Track length & Area covered & 0.530 & 0.467 \\
Track length & Time in middle & -7.34 & 0.007 \\
Track length & Activity & 8.51 & 0.004 \\
Activity & Order caught & 0.070 & 0.791 \\
Activity & Area covered & 0.781 & 0.377 \\
Activity & Time in middle & -7.86 & 0.005 \\
Order caught & Time in middle & 0.002 & 0.964 \\
Order caught & Area covered & 0.04 & 0.841 \\
Time in middle & Area covered & 2.59 & 0.108 \\
Emergence & Track length & 0.312 & 0.576 \\
Emergence & Activity & 0.224 & 0.636 \\
Emergence & Order caught & 0.504 & 0.478 \\
Emergence & Area covered & 0.946 & 0.331 \\
\hline
\end{tabular}

Among-individual covariance $\left(\mathrm{COV}_{\mathrm{I}}\right)$ was tested in each case by likelihood ratio test comparison of a bivariate mixed models with $\mathrm{COV}_{\mathrm{I}}$ freely estimated to one in which $\mathrm{COV}_{\mathrm{I}}$ was constrained to equal zero. We assume twice the difference in model log-likelihood is distributed as $\chi_{1}^{2}$.

Table A3.

Eigen vector decomposition of the among-individual variance-covariance matrix (I) for behavioural traits as estimated from the multivariate mixed model.

\begin{tabular}{lccccrr}
\hline & Eigen 1 & Eigen 2 & Eigen 3 & Eigen 4 & Eigen 5 & Eigen 6 \\
\hline Eigen values & 0.983 & 0.554 & 0.336 & 0.199 & 0.009 & 0.001 \\
$\begin{array}{l}\text { Percentage variance } \\
\quad \text { explained }\end{array}$ & 47.2 & 26.6 & 16.2 & 9.58 & 0.409 & 0.032 \\
Trait loadings & & & & & & \\
$\quad$ Emergence & 0.159 & -0.410 & 0.660 & 0.607 & 0.045 & 0.024 \\
$\quad$ Track length & 0.546 & 0.118 & -0.139 & 0.122 & -0.688 & 0.424 \\
Activity & 0.624 & 0.154 & -0.062 & 0.033 & 0.072 & -0.760 \\
Order & 0.198 & 0.051 & 0.651 & -0.725 & -0.042 & 0.084 \\
Area covered & 0.093 & 0.810 & 0.198 & 0.269 & 0.388 & 0.272 \\
$\quad$ Time in middle & -0.490 & 0.367 & 0.281 & 0.132 & -0.606 & -0.401 \\
\hline
\end{tabular}


Table A4.

Statistical inference of among-individual covariance terms between standard length (SL) and each behavioural trait.

\begin{tabular}{llc}
\hline Behavioural trait & $\chi_{2}^{2}$ & $P$ \\
\hline Emergence & 2.49 & 0.288 \\
Track length & 2.26 & 0.322 \\
Activity & 1.95 & 0.377 \\
Order caught & 2.348 & 0.309 \\
Area covered & 6.053 & 0.048 \\
Time in middle & 1.78 & 0.411 \\
\hline
\end{tabular}

Note: SL is modelled as a reaction norm with both intercept (size) and slope (growth) terms. Among-individual covariance $\left(\mathrm{COV}_{\mathrm{I}}\right)$ was tested in each case by likelihood ratio test comparison of a bivariate mixed models with $\mathrm{COV}_{\mathrm{I}}$ freely estimated between behaviour and both $\mathrm{SL}_{\text {intercept }}$ and $\mathrm{SL}_{\text {slope }}$ to one in which both behaviour-SL covariance terms were constrained to equal zero. We assume twice the difference in model log-likelihood is distributed as $\chi_{2}^{2}$. 